\title{
Authors' Reply to: COVID-19 as a "Force Majeure" for Non-COVID-19 Clinical and Translational Research. Comment on "Analysis of Scientific Publications During the Early Phase of the COVID-19 Pandemic: Topic Modeling Study"
}

\author{
Andreas Älgă $^{1,2}, \mathrm{MD}, \mathrm{PhD}$; Oskar Eriksson ${ }^{3}, \mathrm{BSc} ;$ Martin Nordberg $^{1}, \mathrm{MD}, \mathrm{PhD}$ \\ ${ }^{1}$ Department of Clinical Science and Education, Södersjukhuset, Karolinska Institutet, Stockholm, Sweden \\ ${ }^{2}$ Department of Global Public Health, Karolinska Institutet, Stockholm, Sweden \\ ${ }^{3}$ DataRobot Inc, Stockholm, Sweden
}

\section{Corresponding Author:}

Andreas Älgå, MD, PhD

Department of Clinical Science and Education, Södersjukhuset

Karolinska Institutet

Sjukhusbacken 10

Stockholm, 11883

Sweden

Phone: 4686161000

Email: andreas.alga@ki.se

\section{Related Articles:}

Comment on: $\underline{\text { https://www.jmir.org/2020/11/e21559 }}$

Comment on: https://www.jmir.org/2021/5/e27937

(J Med Internet Res 2021;23(5):e29156) doi: 10.2196/29156

\section{KEYWORDS}

COVID-19; SARS-CoV-2; coronavirus; pandemic; topic modeling; research; literature; medical research; publishing; force majeure

\begin{abstract}
We thank Petar Milovanovic and Igor Dumic [1] for raising the complex issue of challenges associated with non-COVID-19-related research. We share their view that many of the effects that the COVID-19 pandemic has had on such research are likely yet to be seen and that researchers and funders need to find pragmatic ways to deal with this new reality. However, some of the authors' suggested actions, such as to adjust endpoints and power calculations, risk compromising research quality and should be done with caution. In times and settings associated with poor preconditions for clinical studies, we encourage researchers to assess the utility of alternative data sources, such as readily available medical image and routine clinical data.
\end{abstract}

We concur with the authors that analysis of open data and computer-based simulations have the potential to play a vital role in the future of medical research, apart from experimental and clinical studies. Additionally, we believe that methods like the one used in our study [2] may also prove to be a way forward. The number of published scientific studies is rapidly increasing, and traditional ways of compiling study results to generate new knowledge are slow and not suitable for these numbers. Therefore, the application of existing machine learning text analysis methods and the development of new ones holds promise of scientific gains not only from existing data but also from already completed studies.

\section{Conflicts of Interest}

None declared.

\section{References}

1. Milovanovic P, Dumic I. COVID-19 as a "Force Majeure" for Non-COVID-19 Clinical and Translational Research. Comment on "Analysis of Scientific Publications During the Early Phase of the COVID-19 Pandemic: Topic Modeling Study". J Med Internet Res 2021 May [FREE Full text] [doi: 10.2196/27937] [Medline: 33989167] 
2. $\quad$ Älgå A, Eriksson O, Nordberg M. Analysis of scientific publications during the early phase of the COVID-19 pandemic: topic modeling study. J Med Internet Res 2020 Nov 10;22(11):e21559 [FREE Full text] [doi: 10.2196/21559] [Medline: $\underline{33031049]}$

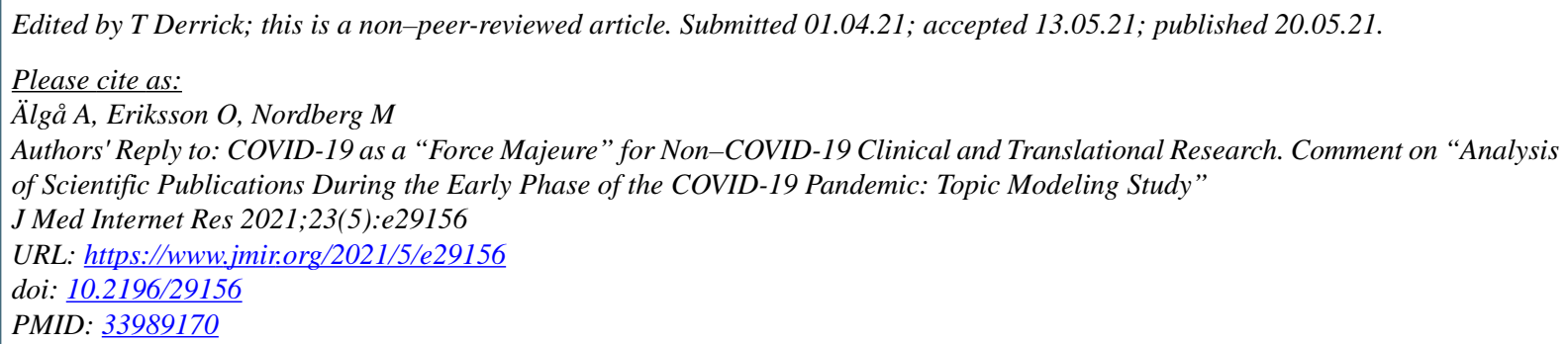

(C)Andreas Älgå, Oskar Eriksson, Martin Nordberg. Originally published in the Journal of Medical Internet Research (https://www.jmir.org), 20.05.2021. This is an open-access article distributed under the terms of the Creative Commons Attribution License (https://creativecommons.org/licenses/by/4.0/), which permits unrestricted use, distribution, and reproduction in any medium, provided the original work, first published in the Journal of Medical Internet Research, is properly cited. The complete bibliographic information, a link to the original publication on https://www.jmir.org/, as well as this copyright and license information must be included. 